Bond University

Research Repository

\title{
Alexithymia, Impulsivity, and Reward Sensitivity in Young Adult University Student Children of Alcoholics
}

Lyvers, Michael; Hayatbakhsh, Niloufar; Stalewski, Janet; Thorberg, Fred Arne

Published in:

Substance Use and Misuse

DOI:

10.1080/10826084.2018.1512628

Licence:

Unspecified

Link to output in Bond University research repository.

Recommended citation(APA):

Lyvers, M., Hayatbakhsh, N., Stalewski, J., \& Thorberg, F. A. (2019). Alexithymia, Impulsivity, and Reward

Sensitivity in Young Adult University Student Children of Alcoholics. Substance Use and Misuse, 54(2), 340-344. https://doi.org/10.1080/10826084.2018.1512628

\section{General rights}

Copyright and moral rights for the publications made accessible in the public portal are retained by the authors and/or other copyright owners and it is a condition of accessing publications that users recognise and abide by the legal requirements associated with these rights.

For more information, or if you believe that this document breaches copyright, please contact the Bond University research repository coordinator 
Parental alcoholism 1

Alexithymia, Impulsivity, and Reward Sensitivity in Young Adult University Student

Children of Alcoholics 


\begin{abstract}
Personality traits previously known as risk factors for alcohol use disorder (AUD) were assessed in 29 young adult children of alcoholics (COAs) and 68 young adult children of non-alcoholics (non-COAs). Male and female university students $\left(M_{a g e}=22.11\right.$ years) completed questions pertaining to demographics and alcohol use, and the Children of Alcoholics Screening Test; Toronto Alexithymia Scale; Barratt Impulsiveness Scale; Sensitivity to Punishment and Sensitivity to Reward Questionnaire; and Depression Anxiety Stress Scales. Results indicated that personality traits of alexithymia, reward sensitivity and impulsivity, as well as negative moods, were significantly elevated in COAs compared to non-COAs, independent of current alcohol consumption and drinking history. Findings are consistent with familial transmission of AUD-associated personality traits in COAs, presumably via influences of genetics and/or familial environment.
\end{abstract}

Keywords: alcohol; impulsivity; alexithymia; reward 
Adult children of alcoholics ${ }^{1}$ (COAs) are at elevated risk of Alcohol Use Disorder (AUD) compared to non-COAs, with evidence implicating personality traits such as impulsivity and reward sensitivity (Littlefield \& Sher, 2010; Slutske et al., 2008) and more recently alexithymia, which refers to difficulties in identifying and describing one's feelings and externalized thinking (Bagby, Parker \& Taylor, 1994; Preece et al., 2017). Dawe and Loxton (2004) suggested that reward sensitivity - presumed to reflect the degree to which the dopaminergic reward system influences behavior - promotes onset of excessive substance use, whereas impulsivity reflects executive dysfunction and promotes maintenance of such use in addictions. Alexithymia has also been linked to executive dysfunction and to COA status (de Haan et al., 2013; Lyvers et al., 2012). In de Haan et al.’s clinical sample of clients with substance use disorders (SUDs; the majority had AUD), alexithymia was elevated among COAs compared to non-COAs, hence the authors concluded that the elevated risk of SUD in COAs may be mediated by alexithymia. If that is the case, then alexithymia - and/or other traits associated with addiction risk, such as reward sensitivity and impulsivity - should be positively associated with COA status even in nonclinical samples. Lyvers et al. (2012) reported that alexithymia and executive dysfunction symptoms such as impulsivity were significantly elevated among COAs and linked to heavier drinking in a nonclinical sample of 314 adults aged 18-45 years. However, as cognitive and emotional deficits of heavy drinkers have sometimes been attributed to brain effects of chronic alcohol exposure (Kopera et al., 2014), the heavier drinking of COAs in the Lyvers et al. study could simply mean that the elevated alexithymia and impulsivity observed in COAs reflected chronic alcohol impacts on the brain rather than pre-alcohol traits.

The present study assessed whether there would be associations of COA status with

\footnotetext{
${ }^{1}$ Present use of the term "children of alcoholics" reflects its widespread use in the relevant research literature; outside of that specific context, "alcohol use disorder" is used herein instead of "alcoholic". 
alexithymia, impulsivity and reward sensitivity in young adult university students who had limited drinking histories, while also controlling for such histories. Alexithymia, impulsivity and reward sensitivity were expected to be elevated in young adult COAs compared to nonCOAs independent of alcohol exposure, consistent with hypothesized familial transmission of such traits.

\section{Method}

\section{Participants}

Online research participation platforms from two universities were used to recruit 105 volunteers, reduced to 97 participants (30 males, 67 females) aged 18-30 years $\left(M_{\text {age }}=22.11\right.$ years, $S D=3.27$ ) after removing 6 multivariate outliers (Mahalanobis distance $p<.001$ ) and 2 cases with incomplete data. The advertisements asked for students aged 18-30 years, who were at least occasional alcohol consumers, to complete an online survey for the incentive of credit towards a psychology subject (22 participants) or a \$25 gift voucher (75 participants). Of the final sample, 29 were identified as COAs, similar to the percentage of children living with a heavy drinking parent according to a recent population study (Manning et al., 2009).

\section{Materials}

The following questionnaires were administered via the online survey hosting platform Qualtrics.

Demographics. There were 11 questions asking for age, gender, education level, drug use, medications, and English proficiency. Two questions assessed alcohol use, (1) "In the past 30 days, on how many days did you have at least one alcoholic beverage?” and (2) “On days when you consumed at least one alcohol beverage, how many such drinks did you typically consume?” This allowed calculation of an alcohol consumption index by multiplying question 1 by question 2 . 
Children of Alcoholics Screening Test (CAST; Jones, 1983). The CAST consists of 30 items with dichotomous scaled responses $(1=$ yes, $0=$ no). Respondents reflect their feelings and experiences related to parental drinking (e.g., "Did you ever wish that a parent would stop drinking?”). Summed affirmative responses give a total score ranging from 0 to 30. The recommended cut-off score for identifying COAs is 6; higher scores indicate greater difficulties arising from parental alcoholism. Cronbach's alpha reliability in the current sample was .97.

Toronto Alexithymia Scale (TAS-20; Bagby et al., 1994). The TAS-20 is a 20-item questionnaire designed to assess alexithymia using a three-factor structure: difficulty identifying feelings (DIF; e.g., “I have feelings that I can’t quite identify”), difficulty describing feelings (DDF; e.g., "It is difficult for me to find the right words for my feelings”), and externally oriented thinking (EOT; e.g., "I prefer talking to people about their daily activities rather than their feelings”). Items are rated on a 5-point Likert scale ( 1 = strongly disagree, 5 = strongly agree). The sum of responses yields a total score ranging 20-100, with higher scores indicating higher alexithymia. Cronbach’s alpha in the current sample was .89.

\section{Sensitivity to Punishment and Sensitivity to Reward Questionnaire (SPSRQ;}

Torrubia, Avila, Molto, \& Caseras, 2001). The SPSRQ is a 48-item index of Gray’s (1982) motivational systems and consists of two 24-item subscales: sensitivity to punishment (SP; e.g., “Are you often afraid of new or unexpected situations?”) and sensitivity to reward (SR; e.g., “Do you often do things to be praised?”). Responses of either yes (1) or no (0) yield a score for each subscale which is a summation of all “yes” responses. Cronbach’s alphas for SP and SR were .88 and .78 , respectively, in the present sample.

Barratt Impulsiveness Scale (BIS-11; Patton, Stanford \& Barratt, 1995). The BIS-11 is a 30-item questionnaire designed to assess trait impulsivity. Items (e.g., “I act on impulse”) are scored on a 4-point Likert scale ( 1 = rarely/never, 4 = almost always/always). A total 
score is obtained through summing item responses. Cronbach's alpha was .86 in the present sample.

Depression Anxiety Stress Scales 21 (DASS-21; Lovibond \& Lovibond, 1995). The DASS-21 is a 21-item questionnaire assessing symptoms of depression, anxiety and stress. Participants respond to each question on a 4-point Likert-scale reflecting the degree to which they experienced each symptom over the past week ( $0=$ Did not apply to me at all, to $3=$ Applied to me very much, or most of the time). There are 7 items each for depression (e.g., "I couldn’t seem to experience any positive feelings at all”), anxiety (e.g., "I felt I was close to panic”), and stress (e.g., "I found it difficult to relax”). An overall score obtained by summing all item responses was used in the present study as an index of negative mood. Cronbach's alpha was .95 in the current sample.

\section{Procedure}

Approval was obtained from the university ethics committees prior to data collection. Participants read an explanatory statement and indicated consent by clicking “I agree,” then measures were presented in randomized blocks. On completion participants sent a screenshot of the final page to obtain their incentive.

\section{Results}

CAST-defined groups had identical gender ratios of 31\% males. COAs reported a later onset age of weekly drinking $(M=19.07$ years, $S D=2.66)$ than non-COAs $(M=18.01$ years, $S D=1.97), t(95)=2.16, p=.033$. As can be seen in Table 1 , overall, CAST scores were positively correlated with SR (but not SP) scores on the SPSRQ as well as BIS-11 impulsivity, DASS-21 negative mood and TAS-20 alexithymia. The latter showed strong positive correlations $^{2}$ with SP, BIS-11 and DASS-21. BIS-11 was positively correlated with

\footnotetext{
${ }^{2}$ A separate, unplanned examination of the TAS-20 subscales indicated that although all three were significantly correlated with the other trait and mood factors in the same way as the total scale score, only the DIF factor was significantly correlated with CAST scores, $r=.35, p<.0001$. 
trait and mood indices. Alcohol consumption was positively correlated with SR and, like SR, was negatively correlated with age at onset of weekly drinking, but was not correlated with CAST scores in this young university student sample.

A 2 X 2 multivariate analysis of covariance was conducted with COA status and gender as independent variables and a drinking history index (current age minus age at onset of weekly drinking) as covariate to control for duration of alcohol exposure. Box’s M and Levene's tests were non-significant, satisfying assumptions. There was a multivariate effect of drinking history on the combined dependent variables, $F(6,87)=3.80, p=.002, \tilde{\eta}^{2}=.21$. After controlling for drinking history there was a multivariate effect of COA status, $F(6,87)$ $=3.16, p=.008, \tilde{\eta}^{2}=.18$, but no effect of gender and no interaction. Univariate tests for COA status were significant for all measures except alcohol consumption $(F<1)$ : BIS-11, $F(1,92)=4.08, p=.046, \tilde{\eta}^{2}=.04 ; \mathrm{SR}, F(1,92)=9.09, p=.003, \tilde{\eta}^{2}=.09 ; \mathrm{SP}, F(1,92)=$ 4.46, $p=.037, \tilde{\eta}^{2}=.05 ;$ TAS-20, $F(1,92)=7.79, p=.006, \tilde{\eta}^{2}=.08 ;$ and DASS-21, $F(1,92)$ $=6.91, p=.010, \tilde{\eta}^{2}=.07$. As shown in Table 2, COAs scored significantly higher on the trait and negative mood indices than did non-COAs ${ }^{3}$, but did not differ on monthly alcohol consumption (which ranged from 4-30 drinks for COAs versus 4-36 drinks for non-COAs).

\section{Discussion}

Present findings were consistent with predictions of elevated levels of negative mood and AUD-associated personality traits of alexithymia, impulsivity and reward sensitivity in young adult COAs. In contrast to previous research indicating heavier drinking among COAs in older community samples (Lyvers et al., 2012), in the present young university student sample current alcohol consumption did not differ between COAs and non-COAs, possibly

\footnotetext{
${ }^{3}$ Although no predictions were made concerning the three subcomponents of alexithymia, for investigative purposes a separate comparison of CAST groups was conducted on the TAS-20 subscales after controlling for drinking history; this MANCOVA indicated that scores on DIF, $F(1,92)=10.84, p=.001, \tilde{\eta}^{2}=.11$, and EOT, $F(1$, $92)=7.28, p=.008, \tilde{\eta}^{2}=.07$, but not DDF, were significantly higher in COAs ( $M_{D I F}=20.62, S D=8.16 ; M_{E O T}=$ $20.83, S D=4.43)$ compared to non-COAs $\left(M_{D I F}=15.37, S D=6.09 ; M_{E O T}=18.63, S D=4.34\right)$.
} 
reflecting social drinking norms at university (Kypri, Cronin \& Wright, 2005), a heavy drinking environment (Gilles, Turk \& Fresco, 2006). In addition, COAs reported a later onset of weekly drinking than did non-COAs, perhaps reflecting their awareness of negative alcohol impacts on their family.

The possibility that traits of COAs in the present sample might reflect chronic alcohol impacts can most likely be excluded because (1) these young adults had only been drinking regularly for a few years; (2) COAs and non-COAs reported similar consumption levels; (3) COAs reported a later drinking onset; and (4) duration of alcohol exposure was controlled by covariate analysis. There remains a possibility, however, that any binge drinking in adolescence that preceded onset of weekly drinking - if at a higher level in COAs - could conceivably have had an impact on brain development in COAs. A recent meta-analysis of brain imaging studies on correlates of alcohol use in adolescence (Feldstein Ewing, Sakhardande \& Blakemore, 2014) concluded that although differences in brain areas concerned with executive function have been found to be associated with adolescent binge drinking, whether or not such differences were causes or effects of drinking cannot be ascertained at present due to the lack of relevant longitudinal studies.

Present findings indicate higher levels of negative mood and AUD-associated traits including alexithymia in young adult COAs after accounting for the duration of weekly alcohol exposure. Both genetics and family environment likely contribute to traits associated with AUD risk in COAs. Alexithymia, impulsivity and reward sensitivity are moderately heritable (Bevilacqua \& Goldman, 2013; Jorgensen et al., 2007); however, an influence of familial environment cannot be excluded, especially for alexithymia given its reported association with poor parental bonding (Thorberg et al., 2011) - a process likely affected by parental alcoholism. Given recent interest in potential therapies to improve executive function 
(Enriquez-Geppert, Hustera, \& Herrmannab, 2013) and alexithymia (Thorberg et al., 2016), such approaches may eventually prove helpful in reducing AUD risk in COAs.

\section{References}

Bagby, R. M., Parker, J. D., \& Taylor, G. J. (1994). The twenty-item Toronto Alexithymia Scale-I. Item selection and cross-validation of the factor structure. Journal of Psychosomatic Research, 38, 23-32. doi: 10.1016/0022-3999(94)90005-1

Bevilacqua, L., \& Goldman, D. (2013). Genetics of impulsive behaviour. Philosophical Transactions of the Royal Society B: Biological Sciences, 368, 20120380. doi: $10.1098 /$ rstb.2012.0380

Dawe, S., \& Loxton, N. J. (2004). The role of impulsivity in the development of substance use and eating disorders. Neuroscience and Biobehavioral Reviews, 28, 343-351. doi: 10.1016/j.neubiorev.2004.03.007

De Haan, H.A., Joosten, E.A.G., de Haan, L., Schellekens, F.A., Buitelaar, J.K., der Palen, J., \& De Jong, C.A.J. (2013). A family history of alcoholism relates to alexithymia in substance use disorder patients. Comprehensive Psychiatry, 54, 911-917. doi: 10.1016/j.comppsych.2013.03.021

Enriquez-Geppert, S., Hustera, R.J., \& Herrmannab, C.S. (2013). Boosting brain functions: Improving executive functions with behavioral training, neurostimulation, and neurofeedback. International Journal of Psychophysiology, 88, 1-16. doi: 10.1016/j.ijpsycho.2013.02.001

Feldstein Ewing, S.W., Sakhardande, A., \& Blakemore, S.J. (2014). The effect of alcohol consumption on the adolescent brain: A systematic review of MRI and fMRI studies of alcohol-using youth. NeuroImage: Clinical, 5, 420-437. doi: 10.1016/j.nicl.2014.06.011 
Gilles, D. M., Turk, C. L., \& Fresco, D. M. (2006). Social anxiety, alcohol expectancies, and self-efficacy as predictors of heavy drinking in college students. Addictive Behaviors, 31(3), 388-398. doi:10.1016/j.addbeh.2005.05.020

Gray, J.A. (1982). The neuropsychology of anxiety: An enquiry into the function of the septo-hippocampal system. New York, NY: Oxford University Press.

Jones, J.W. (1983). Children of Alcoholics Screening Test, (CAST). Chicago: Camelot. Jorgensen, M. M., Zachariae, R., Skytthe, A., Kyvik, K. (2007). Genetic and environmental factors in alexithymia: A population-based study of 8785 Danish twin pairs. Psychotherapy and Psychosomatics, 76, 369-375. doi:10.1159/000107565

Kopera, M., Glass, J.M., Heitzeg, M.H., Wojnar, M., Puttler, L.I., \& Zucker, R.A. (2014). Theory of mind among young adult children from alcoholic families. Journal of Studies on Alcohol and Drugs, 75, 889-894. doi: 10.15288/jsad.2014.75.889

Kypri, K., Cronin, M., \& Wright, C. (2005). Do university students drink more hazardously than their non-student peers? Addiction, 100, 713-714. doi: 10.1111/j.1360-0443.2005.01116.x

Littlefield, A.K., \& Sher, K. J. (2010). The multiple, distinct ways that personality contributes to Alcohol Use Disorders. Social \& Personality Psychology Compass, 4(9), 767-782. doi: 10.1111/j.1751-9004.2010.00296.x

Lovibond, S. H., \& Lovibond, P. F. (1995). Manual for the Depression Anxiety Stress Scales. Sydney, NSW: Psychological Foundation.

Lyvers, M., Onuoha, R., Thorberg, F. A., \& Samios, C. (2012). Alexithymia in relation to parental alcoholism, everyday frontal lobe functioning and alcohol consumption in a non-clinical sample. Addictive Behaviors, 37, 205-210. doi: 10.1016/j.addbeh.2011.10.012

Manning, V., Best, D.W., Faulkner, N., \& Titherington, E. (2009). New estimates of the 
number of children living with substance misusing parents: Results from UK national household surveys. BMC Public Health, 9, 377. doi: 10.1186/1471-2458-9-377.

Patton, J. H., Stanford, M. S., \& Barratt, E. S. (1995). Factor structure of the Barratt Impulsiveness Scale. Journal of Clinical Psychology, 51, 768-774. Retrieved from: http://www.ncbi.nlm.nih.gov/pubmed/8778124

Preece, D., Becerra, R., Allan, A., Robinson, K., \& Dandy, J. (2017). Establishing the theoretical components of alexithymia via factor analysis: Introduction and validation of the attention-appraisal model of alexithymia. Personality \& Individual Differences, 119, 341-352. doi: 10.1016/j.paid.2017.08.003

Slutske, W.S., D’Onofrio, B.M., Turkheimer, E., Emery, R.E., Harden, K.P., Heath, A.C., \& Martin, N.G. (2008). Searching for an environmental effect of parental alcoholism on offspring alcohol use disorder: A genetically-informed study of children of alcoholics. Journal of Abnormal Psychology, 117, 534-551. doi: 10.1037/a0012907

Spinella, M. (2003). Relationship between drug use and prefrontal-associated traits. Addiction Biology, 8, 67-74. doi: 10.1080/1355621031000069909

Thorberg, F. A., Young, R. M., Sullivan, K. A., \& Lyvers, M. (2009). Alexithymia and alcohol use disorders: A critical review. Addictive Behaviors, 34, 237-245. doi: 10.1016/j.addbeh.2008.10.016

Thorberg, F.A., Young, R., Sullivan, K.A., \& Lyvers, M. (2011). Parental bonding and alexithymia: A meta-analysis. European Psychiatry, 26(3), 187-193. DOI: 10.1016/j.eurpsy.2010.09.010

Thorberg, F. A., Young, R. McD., Sullivan, K. A., Lyvers, M., Hurst, C., Connor, J.P., Tyssen, R., London, E.D., Noble, E.P., \& Feeney, G.F.X. (2016). A prospective mediational study on the stability of alexithymia among alcohol-dependent outpatients in Cognitive-Behavioral Therapy. Psychology of Addictive Behaviors, 
Parental alcoholism 12

30, 64-72. doi: 10.1037/adb0000135

Torrubia, R., Ávila, C., Moltó, J., \& Caseras, X. (2001). The Sensitivity to Punishment and Sensitivity to Reward Questionnaire (SPSRQ) as a measure of Gray’s anxiety and impulsivity dimensions. Personality and Individual Differences, 31, 837-862. doi: 10.1016/S0191-8869(00)00183-5 
Table 1

Means, standard deviations and intercorrelations of variables (see text for definitions).

\begin{tabular}{|c|c|c|c|c|c|c|c|c|}
\hline & 1 & 2 & 3 & 4 & 5 & 6 & 7 & $M(S D)$ \\
\hline 1. Alcohol Consumption & - & & & & & & & $12.21(6.71)$ \\
\hline 2. Drinking Onset Age & $-.30 * *$ & - & & & & & & $18.33(2.24)$ \\
\hline 3. CAST & .05 & .18 & - & & & & & $5.21(8.01)$ \\
\hline 4. BIS-11 & .14 & -.10 & $.20^{*}$ & - & & & & $63.13(11.81)$ \\
\hline 5. DASS-21 & .13 & .11 & $.30 * *$ & $.49 * *$ & - & & & $17.58(14.20)$ \\
\hline 6. SP & -.13 & .14 & .17 & $.28 * *$ & $.52 * *$ & - & & $14.22(5.87)$ \\
\hline 7. SR & $.26 *$ & $-.21 *$ & $.32 * *$ & $.38 * *$ & .17 & .15 & - & $11.84(4.41)$ \\
\hline 8. TAS-20 & .15 & .10 & $.26 * *$ & $.55^{* *}$ & $.63^{* *}$ & $.47 * *$ & .12 & 50.49 (13.83) \\
\hline
\end{tabular}

$N=97 .{ }^{*} p<.05,{ }^{* *} p<.01$ 
Table 2

Comparison of Children of Alcoholics (COAs) and Children of Non-Alcoholics (non-COAs) on Trait, Mood and Drinking Variables.

\begin{tabular}{lccc}
\hline & COAs $[M(S D)]$ & & Non-COAs $[M(S D)]$ \\
& $(n=29)$ & $(n=68)$ \\
\hline Alexithymia & $56.28(14.73)$ & $* *$ & $48.01(12.75)$ \\
Reward Sensitivity & $13.72(4.62)$ & $* *$ & $11.03(4.09)$ \\
Punishment Sensitivity & $15.69(4.87)$ & $*$ & $13.59(5.87)$ \\
Negative Mood & $24.90(16.68)$ & $* *$ & $14.46(11.81)$ \\
Impulsivity & $67.03(12.32)$ & $*$ & $61.47(11.27)$ \\
Alcohol Consumption & $12.97(6.81)$ & & $11.88(6.69)$ \\
& & & \\
\hline
\end{tabular}

${ }^{*} p<.05,{ }^{* *} p<.01$. 